\title{
EDUCAÇÃO ATIVA: PROTAGONISMO, INTERPESSOALIDADE E DIÁLOGO
}

\author{
*Gabriel César Dias Lopes
}

\section{Resumo}

Em um país como o Brasil onde a educação é notadamente marcada pelos ranços do colonialismo e do tradicionalismo, a proposta de uma Educação Ativa tem se mostrado coerente com as necessidades do homem atual e com as demandas de uma sociedade cada dia mais desafiadora quanto à aprendizagem significativa e significadora. Este artigo, trata do conceito de Educação Ativa a partir de uma pesquisa bibliográfica com os principais articuladores da proposta e usando uma abordagem qualitativa e descritiva historiciza os primórdios dessa ideia bem como busca no contexto atual analisar de forma crítica as possibilidades e os entraves para a implantação desse modelo que articula conhecimento, protagonismo individual e responsabilização pela própria aprendizagem e espírito de cooperação e equipe. Os resultados dessa avaliação apontam para não somente a viabilidade do modelo como também a sua pertinência e necessidade no atual contexto.

Palavras-Chave: Educação Ativa, Protagonismo, Aprendizagem.

\section{Abstract}

In a country as Brazil where the education is marked by the ranços of the colonialism and the traditionalism, the proposal of an Active Education if has shown coherent with the necessities of the current man and with the demands of a society each more challenging day how much to the significant and significadora learning. This article, deals with the concept of Active Education from a bibliographical research with the main articuladores of the proposal and using a qualitative and descriptive boarding historiciza the primórdios of this idea as well as search in the current context to analyze of critical form the possibilities and the impediments for the implantation of this model that articulates knowledge, individual protagonism and responsabilização for the proper learning and spirit of cooperation and team. The results of this evaluation not only point with respect to the viability of the model as well as its relevancy and necessity in the current context.

Word-Key: Active education, Protagonism, Learning.

\section{Resumen}

En un país como Brasil en donde el notadamente de la educación es marcado por los ranços del colonialismo y el traditionalism, la oferta de una educación activa si ha demostrado coherente con las necesidades del hombre actual y con las demandas de una sociedad cada día más desafiador cuánto a aprender significativo y del significadora. Este artículo, repartos con el concepto de la educación activa de una investigación bibliográfica con los articuladores principales de la oferta y de usar un historiciza que sube cualitativo y descriptivo los primórdios de esta idea así como búsqueda en el contexto actual de analizar de forma crítica las posibilidades y los impedimientos para la implantación de este modelo que articula conocimiento, protagonism individual y el responsabilização para aprender y el alcohol 
apropiados de la cooperación y del equipo. Los resultados de esta evaluación no sólo señalan con respecto a la viabilidad del modelo así como su importancia y de la necesidad en el contexto actual.

Palabra-Llave: Educación activa, Protagonism, aprendizaje.

* Prof. Dr. Gabriel César Dias Lopes, Ph.D possui Graduação em Teologia, Direito, Administração e Recursos Humanos, MBA em Marketing e Gestão Estratégica, Mestrado em Educação, Mestrado em Administração, Doutorado em Educação e um Ph.D em Psicanálise. Membro da International Special Court of Arbitration and Human Rights - Registro: ISCAHRGCDL-17/11n-2016, Membro da Comissão Científica da Olympus Intellectual Center, Atenas (Grecia), Presidente da LUI - Logos University International. 


\section{Introdução}

Entende-se por Educação Ativa aquela que se pauta na responsabilização do aluno pelo seu próprio projeto de estudos tornando-o protagonista de seu próprio processo de aprendizagem, incorporando em suas ações a integração entre os indivíduos no seu entorno compreendendo sua prática e de outrem e gerenciando seus talentos e os recursos disponíveis, a estudar previamente o conteúdo do tema em questão e a trabalhar em equipe, em prol de um resultado prático, com significado e que todos desejam.

A proposta parece aquela que mais se aproxima das demandas contemporâneas, porém ainda encontra resistência em sua abordagem por aqueles setores da educação ainda pautados no modelo tradicional de educação ou mesmo naqueles que não conseguiram avançar em transições de modelos que não se firmaram mas que persistem na prática das salas de aula. Nesse artigo propõe-se avaliar os pressupostos da Educação Ativa, suas possibilidades diante do modelo atual de educação, mas principalmente diante do indivíduo que aí está e daquele que se espera formar.

Weltman (2007, p.7) enfatiza que não existe na literatura uma origem clara de quem foi o inventor desta prática, desde o inglês Inglês R.W. Revans com o objetivo de se promover um método educativo, oportunizando crianças a se desenvolverem para uma educação integral , até Dewey que desde os primórdios do século XX tinha como "objetivo era de formar os estudantes para uma vida mais democrática, muitos foram aqueles que intentaram sobre a prática de uma educação mais inclusiva.

O conceito de Educação Ativa porém foi sistematizado e dimensionado pelos PHDs em História e Psicologia, os americanos Charles C. Bonwell e James A. Eison. Remonta a 1991 nos EUA. Na verdade, de maneira simplificada envolve o conceito de ação-reflexão-ação no qual eles afirmam que Educação Ativa pode ser definida como "Qualquer coisa que envolva os alunos em fazer as coisas e pensar sobre as coisas que estão fazendo.” Bonwell \& Eison.

Essa ideia está diretamente ligada a necessidade de rever as práticas tradicionais de sala de aula que já não alcançavam em todas as dimensões o aluno em questão.

Conforme Bonwell e Eison (1991) o avanço tecnológico advindo principalmente a partir da globalização permitiu a gênese de um novo tipo de individuo que precisa de maiores estímulos e de uma maior responsabilização com sua aprendizagem para tanto, as instituições de ensino precisaram passar por uma revisão de seus conceitos e práticas passando a utilizar metodologias que estivessem mais próximas a esses alunos em sala de aula. 
Ainda para esses autores ficava nítida que a metodologia usada até então pautado no ensino enquanto transmissão de conhecimentos, falhavam em termos de absorção, entendimento e aplicação dele, ou seja, a real apreensão do conhecimento uma vez que se pautavam em memorização e em avaliações parciais e desconectadas com a vivência dos alunos.

Longe de erradicar o modelo tradicional ainda arraigado na realidade educacional do país e traduzidos nas famosas provas, testes e avaliações, a Educação Ativa vem aos poucos trazendo possibilidades que perpassam sobre uma dinâmica educacional que alia os interesses do educando com as demandas cotidianas e principalmente possibilitando que o processo ensino-aprendizagem se torne além de mais dinâmico, cooperativo, integrado e porque não dizer mais holístico, uma vez que torna possível uma maior aproximação do aluno com os professores , agora, orientadores e não transmissores e também com a equipe escolar como um todo.

Com esta proposta estão conectadas as chamadas competências do século 21 que requerem além da competência cognitiva do indivíduo, que seja desenvolvida e incentivado o seu desenvolvimento socioemocional, visto que se entende que está nas relações, interpessoais e intrapessoais o maior desafio de convivência da humanidade.

\section{Educação Ativa, uma história, um devir}

Atentos ao conceito proposto por Bonwell e Eison (1991) pode-se traduzir a Educação Ativa como uma parceria entre professor e aluno na busca pelo conhecimento. Entendida enquanto uma metodologia focada no diálogo, na sondagem de conhecimentos, comportamentos e competências prévias, bem como nas percepções sobre as temáticas propostas. É também pautada nas chamadas competências do século 21 , que envolve principalmente o desenvolvimento emocional, social e ético do indivíduo.

Sua proposta envolve partir da problematização, para a contextualização e aplicação prática dos conhecimentos envolvendo principalmente o desenvolvimento de competências valorativas do ser humano, ou seja, competências pessoais de cunho de valor, tendo como consequência direta a elevação da capacidade do indivíduo em desenvolver competências científicas ou técnicas.

Nesse sentido o aprender envolve o entender. As capacidades outrora valoradas de memorização pura e simples aqui são descartadas e substituídas pelo entendimento. O 
entendimento passa a ser o cerne da aprendizagem e essa por sua vez vem a ser mensurada pela elevação do individuo não somente enquanto técnico, mas como um ser humano, com todas as competências e valores desenvolvidos potencialmente.

A ênfase dada à mudança de comportamento advindas através da atribuição dessas competências pessoais são tratadas como processo imprescindível no contexto da aprendizagem através de uma Educação Ativa. Para Bonwell e Eison (1991) a responsabilidade pelo próprio aprender é também um conceito de liberdade de escolha que impulsiona a autoestima, o respeito, o comprometimento do indivíduo, a afetividade, e a empatia que facilitará o trabalho em grupo que é uma das metodologias principais a serem utilizadas por esse modelo de educação.

Nesse contexto de protagonismo enunciada por esses valores, o aluno passa a ser sujeito ativo no seu processo e tem a consciência de que o professor é mediador, facilitador, estimulador do processo, mas apenas a si próprio cabe a tarefa de criar seu contexto e possibilidades de aprendizagem. Isso não retira a importância nem diminui o papel do professor nessa dinâmica. Ao contrário, o seu papel de sensibilizador é inequívoco.

\subsection{O professor no contexto da Educação Ativa}

O processo de envolver o aluno e responsabilizá-lo por sua a própria aprendizagem, não diminui a tarefa do professor nem o onera do trabalho como é entendido por muitos. Ao contrário, o processo que leva à autonomização do aluno exige que o professor possua competências ainda mais complexas e muito além da capacidade de transmitir conhecimentos. Afinal mediar a aprendizagem requer muito mais empenho, dedicação, estudo e responsabilidade sobre sua própria história e sobre a formação do outro. Não se pode sair do tradicionalismo e cair em metodologias equivocadas, sem fundamentos ou direcionamentos.

Para tanto, Bonwell e Eison (1991), atestam que há algumas considerações acerca dos valores e comportamentos que se espera do professor. Em primeiro lugar reconhecer seu valor próprio, sua história, sua cultura seriam os primeiros comportamentos esperados para alguém que se reconheça enquanto ser humano.

Quanto à dimensão pedagógica, a fïrmeza e a consciência de sua capacidade técnica facilitarão o seu fazer metodológico e trará confiança aos alunos, ajudando a também despertar autoconfiança, autoconsciência e respeito. Não se trata aqui da obrigação de motivar o aluno. O próprio conceito de motivação é dúbio e discutível. Trata-se do professor que com seu 
comportamento motivado traduzido no seu fazer metodológico com conteúdos diferenciados, com postura compreensiva e de respeito às diferenças, com interesse pelas vivências dos alunos, motivará os alunos não apenas no discurso, mas no comportamento apresentado evidenciado em sala de aula.

Como relata Nóvoa (2011, p.08):

\begin{abstract}
Estamos a assistir, neste início do século XXI, a um regresso dos professores ao centro das preocupações educativas. Os anos 70 foram marcados pela racionalização do ensino, a pedagogia por objetivos, a planificação. Os anos 80 pelas reformas educativas e pela atenção às questões do currículo. Os anos 90 pela organização, administração e gestão dos estabelecimentos de ensino. Agora, parece ter voltado o tempo em que os professores se tornam o cerne da questão.
\end{abstract}

É notório, que a educação brasileira tem na sua estrutura característica um modelo onde o que é valorizado é a produção do conhecimento, e de fato, esse conhecimento é transmitido, mas o pedagógico e o socioemocional vem sendo negligenciado. Não podemos culpar apenas às instituições, pois há uma inexistência de amparo legal que estimule a formação pedagógica pautados também nessas competências socioemocionais para esses docentes.

Muitos professores se comportam como especialistas, atuando apenas na sua área de conhecimento e entende que sua experiência durante a carreira acadêmica, fará com que eles tenham uma qualificação didático-pedagógica, o que não é verdade. É claro que a experiência acumulada durante anos de prática docente é importante, mas ela por si só não é suficiente para o processo de construção do conhecimento por parte dos alunos.

É preciso considerar que a atividade profissional de todo docente possui uma natureza pedagógica, isto é, vincula-se a objetivos educativos de formação humana e a processos metodológicos e organizacionais de construção e apropriação de saberes e modos de atuação. Pimenta e Anastasiou (2003), afirmam que, embora os professores possuam experiências significativas e trajetória de estudos em sua área de conhecimento específica, é comum nas diferentes instituições de ensino o predomínio do "despreparo e até um desconhecimento científico do que seja o processo de ensino e de aprendizagem, pelo qual passam a ser responsáveis a partir do instante em que ingressam na sala de aula".

Para exercer a docência, é necessário que o profissional além de ter conhecimentos específicos da sua formação, também possua conhecimentos pedagógicos do processo ensinoaprendizagem, aliados aos saberes de sua experiência e de sua produção científica, pois quando um docente tem formação pedagógica, ele traz consigo uma fonte de aprendizagem numa perspectiva de mudança e inovação para a sala de aula, contribuindo de forma significativa para a transformação do conhecimento e sua aplicabilidade, aos discentes. 
Para Esteve (2009):

Há um autêntico processo histórico de aumento das exigências que se fazem ao professor pedindo-lhe que assuma um número cada vez maior de responsabilidades. [...] Para além da matéria que leciona, pede-se ao professor que seja um facilitador da aprendizagem, pedagogo eficaz, organizador do trabalho de grupo, e que, para além do ensino, cuide do equilíbrio psicológico e afetivo do aluno, da integração social e da educação sexual etc. (ESTEVE, 2009, p. 100).

Estas exigências educacionais são consequência das grandes transformações que ocorreram nas últimas décadas e que envolvem a competitividade e a luta pelo domínio do saber, características do estado neoliberal. Assim, em uma época onde a sociedade contemporânea vem transformando a educação em algo lucrativo e rentável, o professor é formado também para o mercado de trabalho, onde desempenhará suas atividades de especialista, e onde muitas vezes questões recorrentes do cotidiano da educação vão sendo obliteradas fazendo cada dia mais necessária a ideia de uma formação continuada, em serviço para que lacunas sejam paulatinamente preenchidas frente as demandas.

Muitas vezes, os professores são coagidos a dominar práticas e saberes, nunca necessário ao desempenho de suas funções na escola. "A pedagogia de projetos, a transversalidade dos currículos, as avaliações formativas, enfim, são muitas as novas exigências que esses profissionais se veem compelidos a responder" (OLIVEIRA, 2007, p. 34).

Neste cabedal de exigências dos sistemas educacionais os professores muitas vezes ficam sem saber se trabalham as bases do conhecimento imprescindíveis para o desenvolvimento do aluno enquanto sujeito de interferência na sociedade, ou se passam a ser "consultores de métodos e animadores de grupos de trabalho" (LABARCA, 1995, p. 175). Nesse sentido a formação em serviço para uma educação ativa é de suma importância.

\subsection{Educação Ativa ou Metodologias Ativas?}

Todo o processo de educação ativa envolve as práticas e metodologias pedagógicas que interfiram na aprendizagem que nesse modelo precisa ser também ativa. Ativa e Interativa uma vez que requer que o aluno participe de todo o processo seja em qualquer disciplina, se engajando e desenvolvendo habilidades que são tão evidenciadas atualmente na BNCC (Base Nacional Comum Curricular) com verbos como escrever, falar, resolver problemas ou refletir entre outros que demonstram o imperativo da ação. 
Dentre as metodologias que tornam esse tipo de ação possível não são desconhecidas em sua existência, o que diferencia nesse modelo é a frequência dessa utilização e o envolvimento do professor-orientador que irá diferenciar na aquisição deste conhecimento por parte do aluno. Entre os modelos de metodologias de ensino ativo, mais usuais temos: Aulalaboratório, trabalhos em grupos, simulações, aprendizagem baseadas em problemas (PBL), utilização de ambientes virtuais e mídias sociais etc.

A metodologia oportuniza a um alto padrão de qualidade de aprendizagem perante uma realidade mútua de comunicação, que é um princípio elementar da aprendizagem ativa (FELDER; BRENT, 2009). A aprendizagem ativa contempla técnicas em que o professor deixa de ser o centro da aprendizagem e passa a ser um mediador. Nesta proposta, por sua vez, o professor tem o papel de "incentivar as crianças a serem ativas em relação à própria aprendizagem e ao desenvolvimento da cognição e da metacognição" e para que isso aconteça, é necessária uma pedagogia "que saliente as habilidades de pensamentos gerais" (VICKERY, 2016, p. 1).

Um dos princípios da aprendizagem ativa é promover a interação entre os estudantes com o propósito de resultar em uma aprendizagem participativa e significativa, dentro e fora de sala de aula, como é o caso da aprendizagem cooperativa e aprendizagem colaborativa (TORRES, 2014)

Entendendo que os ambientes de aprendizagem são fundamentais no desenvolvimento das competências de cognição, interpessoalidade e principalmente intrapessoalidade tão esperadas para o sujeito do século 21 esse tipo de atividade além de possibilitar resultados interessantes, pautados no envolvimento de ambos, aluno e professor a técnica utilizada em sí refletirá ao educando a mensagem de respeito aos seu interesses por parte da instituição e por parte do professor.

\subsection{Dificuldades na utilização das Metodologias Ativas}

Mesmo com todas os pontos positivos elencados, a utilização desse tipo de metodologia encontra resistência tanto do aluno quanto do professor para a sua utilização. O hábito de uma educação bancária não se desfaz rapidamente e traz acomodação tanto ao aluno quanto ao professor. Ao professor, o sair da sua zona de conforto e a necessidade de reciclar, reaprender, e principalmente aprender a melhor instrumentalizar seus saberes. Ao aluno a insegurança e a alienação quanto ao verdadeiro sentido de aprendizagem ativa e significada por sua própria 
busca.

Quando se diz que o professor precisa reciclar isso infere que ele tenha uma melhor preparação pois subentende-se que o aluno ativo estará também mais preparado. É preciso que ambos tenham clareza desse tipo de metodologia e isso envolve diálogo pois à primeira vista o plano pedagógico parecerá ao aluno que o professor não quer trabalhar e está transferindo o esforço para eles.

\begin{abstract}
Atualmente, percebe-se a presença de um forte contingente de professores, das mais diversas áreas, com amplo conhecimento científico, mas sem nenhuma habilidade de educar e organizar a prática pedagógica que realiza em sua ação docente. Além disso, esperamos ver no professor o reflexo de um profissional comprometido com as mudanças exigidas de cada indivíduo, uma caminhada que auxilia na organização de suas propostas, para atuar, participar e transformar sua realidade. (RIVERO, 2004, p.85).
\end{abstract}

Nessa percepção, a formação pedagógica do professor é pensada como aperfeiçoamento da ação docente em processo de educação inicial e continuada. Nesse sentido, para ser docente é preciso muito mais do que apenas conhecer sua área de atuação, mas principalmente, é preciso adquirir conhecimento, competências e desenvolver habilidades que viabilizem o aprendizado na linha de valores éticos e da reflexão epistemológica, reflexão esta que trata da natureza, da origem e validade do conhecimento, e estuda também o grau de certeza do conhecimento cientifico nas suas diferentes áreas, com o objetivo principal de estimar a sua importância para o espírito humano.

Assim sendo, o protagonismo de ambos é indispensável, ambos precisam se responsabilizar pelo processo pois só isso garantirá o aprendizado, visto que esse é o maior problema desse tipo de metodologia: a mensuração da aprendizagem de forma equitativa. Notadamente todos saem ganhando caso esse envolvimento de todas as partes seja conseguido.

\title{
3 Considerações Finais
}

O modelo da Educação Ativa surge conforme cresce a necessidade de mudança nas práticas acadêmicas em todos os níveis de ensino. Apesar de não parecer uma prática nova por ser eventualmente utilizada em sala de aula, sua prática sistemática não é observada de forma geral e ainda é tida com desconfiança por aqueles menos propensos a mudanças.

Fato é que conforme sugere a metodologia de Educação Ativa o aluno é responsabilizado pelo seu projeto de aprendizagem tornando-se protagonista do mesmo, em um processo de diálogo interatividade, cognição e socialização com resultados práticos individuais 
e coletivos que trazem ao ensino um misto de prazer e dever cumprido indispensáveis ao crescimento do indivíduo.

Portanto, para realizar um trabalho didático-pedagógico condizente com a realidade que está inserido, o professor deve ter um perfil baseado nas reais situações relativas à docência. Não há como adquirir status de uma profissão se a atividade didático-pedagógica permanecer em segundo plano ou se a escolha for por falta de opção.

O professor que acredita na causa e reconhece suas limitações e as necessidades de seus alunos e da sociedade, como responsável pela formação de outros, deve ter as suas capacidades potencializadas mediante a formação permanente e continuada e com um aprofundamento em pesquisas em seu campo de atuação.

O docente necessita compreender que o ato educativo se realiza a partir de vários elementos que circundam a vida do sujeito, desenvolvendo um processo de ensinoaprendizagem que satisfaçam os anseios deles, por isso, a sua atuação pedagógica deve ser revista constantemente a fim de corroborar com a formação desse sujeito.

Apenas com profissionais capazes de buscar respostas para essas expectativas ter-se-á o sucesso que se espera na formação dos futuros profissionais e sobretudo seres humanos em contínua formação. Sendo assim, é possível uma Educação Ativa, mas antes de tudo, consciência e engajamento. 


\section{Referencias}

BONWELL, C. C., \& EISON, J. A. (1991). Active learning: Creating excitement in the classroom. Washington DC: George Washington University.

ESTEVE, José Manuel. Mudanças sociais e função docente. In: Nóvoa, Antônio (org). Profissão professor. Porto: Porto Editora, 2009.

FELDER, Richard M. BRENT, Rebecca. Active Learning: An Introduction. ASQ Righer Education Brief, 2(4) 2009. Disponível em: 11899 Acesso em: 11 mai. 2015.

GUDWIN, Ricardo. Aprendizagem Ativa. Disponível em: http://faculty.dca.fee.unicamp.br/gudwin/activelearning Acesso em: 27 set. 2015.

LABARCA, Guilhermo. Cuánto se puede gastar em educación ? Revista de La Cepal. $\mathrm{n}^{\circ}$ 56, p 163-178. Agosto 1995.

NÓVOA, António. Formação de professores e profissão docente. Disponível em: http://core.ac.uk/download/pdf/12424596.pdf\&gt. Acesso em 26 set 2015.

. Formação de professores e trabalho pedagógico. Lisboa: EDUCA, 2002.

OLIVEIRA, Dalila Andrade. Reformas educacionais na América Latina e os trabalhadores docente. Belo Horizonte. Autêntica, 2007.

PIMENTA,S,G. ANASTASIOU,L. das G.C. Docência no ensino superior. São Paulo, Cortez 2002.

PIMENTA,S.G. Formação de professores: saberes da docência e identidade do professor. Revista da Faculdade de Educação. USP. V 1. № 1, p 72-89. Jul-dez, 2011.

RIVERO. C, GALLO, S. A formação de professores na sociedade do conhecimento. Bauru, SP: Edusc, 2004.

TORRES, Patrícia Lupion. Laboratório on-line de aprendizagem: uma proposta crítica de aprendizagem colaborativa para a educação. Tubarão: Ed. Unisul, 2004.

VICKERY, Anitra. et al. Aprendizagem Ativa: nos anos iniciais do ensino fundamental. Porto Alegre: Penso, 2016. 252p.

WELTMAN, David. A comparision of traditional and active learning methods: an empirical investigation utilizing a linear mixed model. 2007. 134f. Tese de Doutorado (Doutorado em Filosofia). The University of Texas at Arlington, 2007. 